\title{
Prognostic Factors in Liver Cirrhosis Patients with Upper Gastrointestinal Bleeding
}

\author{
Adrian Goldis $^{1}$, Raluca Lupusoru ${ }^{1,2}$, Ramona Goldis ${ }^{3 *}$ and lulia Ratiu ${ }^{1}$ \\ ${ }^{1}$ Department of Gastroenterology and Hepatology, "Victor Babes" University of Medicine and Pharmacy, Timisoara, Romania \\ ${ }^{2}$ Department of Biostatistics and Medical Informatics, "Victor Babes" University of Medicine and Pharmacy, Timisoara, Romania \\ ${ }^{3}$ Algomed Policlinic, Timisoara, Romania
}

*Corresponding author: Ramona Goldis, Algomed Policlinic, 4, Lucian Blaga Street, 300002, Timişoara, Romania, Tel: + 40-722-410712; Fax: + 40-256-431178; Email: goldisadi@yahoo.com, amalia_goldis@yahoo.com

Received date: October 30, 2017; Accepted date: November 23, 2017; Published date: November 30, 2017

Copyright: (C) 2017 Goldis A, et al. This is an open-access article distributed under the terms of the creative Commons Attribution License, which permits unrestricted use, distribution and reproduction in any medium, provided the original author and source are credited.

\begin{abstract}
Introduction and aim: Upper gastrointestinal bleeding (UGB) remains one of the frequent problems in medical practice, that especially on patient with hepatic cirrhosis, has a major significance due to its determined mortality and morbidity. The aim of this study was to analyze the upper gastrointestinal bleeding in liver cirrhotic patients and to assed the different parameters as possible prognostic factors for mortality in those patients.
\end{abstract}

Material and methods: We have made a retrospective study on 647 patients with liver cirrhosis patients hospitalized for UGB episode in a 5 years period in Gastroenterology and Hepatology Clinic of the Emergency Clinical County Hospital Timisoara.

The liver cirrhosis diagnostic of the patients included in the study was determined by clinical exam together with paraclinical tests (laboratory and imagistic), or by histological exam.

Results: The studied group included 647 hepatic cirrhosis patients, hospitalized for upper digestive hemorrhage ( 352 men-54.4\% and 295 women $-45.5 \%$ ), aged between 16 and 84 years with an average age of $54.5 \pm 26.1$ years old. Almost $70 \%$ of the patients $(n=447)$ had variceal hemorrhage; $83 \%(n=369)$ of these, bled because of the esophageal varices rupture and $17 \%(n=78)$ because of the gastric ones. Almost $70 \%$ of the cases had active bleeding during endoscopy and $20 \%$ had hemorrhagic shock. Death rate was $17 \%$. We evaluated the possible predictive factors for early mortality and rebleeding in patients with variceal hemorrhage, by dividing the batch of 647 patients into 2 categories as follows: Patients without rebleeding $(\mathrm{N}=289)$ vs. patients who rebleed $(\mathrm{N}=158)$ and Survivors $(\mathrm{N}=370)$ vs. deceased $(\mathrm{N}=77)$, we tried to identify possible risk factors for prediction of rebleeding and early mortality by analyzing the following parameters: the degree ofhepatic insufficiency (Child-Pugh classification and MELD score, albumin, cholinesterase, bilirubin), the severity of bleeding (anemia, hemorrhagic shock,), endoscopic parameters (variceal grade, active bleeding at endoscopy), coagulation disorders (platelets count and INR), etiology of cirrhosis, decompensation of the underlying disease (vascular, parenchymatous).

Conclusion: MELD score, serum albumin level, encephalopathy, severe anemia and rebleeding are prognostic factors for mortality and the predictive factors for rebleeding in cirrhotic patients with variceal hemorrhage are MELD score and large ascites.

Keywords: Liver cirrhosis; Gastrointestinal bleeding; Medical practice; Prognostic factors

\section{Introduction}

Upper gastrointestinal bleeding (UGB) remains one of the frequent problems in medical practice, that especially on patient with liver cirrhosis, has a major significance due to its determined mortality and morbidity.

The complications and mortality after the first UGB on the cirrhotic patient can be determined by multiple factors: the source of hemorrhage(the rupture of esophageal varices, gastric or duodenal ulcer, portal-hypertensive gastropathy, the rupture of the gastric varices, hemorrhagic gastritis, Mallory-Weiss syndrome, etc.), the gravity of the hemorrhage (hemodynamic impact, etc.), aggravation of the hepatic failure (appreciated by Child-Pugh criteria), other pathologies association (infections, diabetes, chronic respiratory diseases).

Even if the prognosis of these patients got well in the last decades, the mortality remains increased, and it's important in variceal hemorrhage) [1,2].

The esophageal varices are the most frequent complications of the portal hypertension, occurring on $60 \%$ of the cirrhotic patients, associated with hospital mortality of $10-20 \%$ [3-5], but these patients have frequently another source of bleeding) [3-5]. 
Citation: Goldis A, Lupusoru R, Goldis R, Ratiu I (2017) Prognostic Factors in Liver Cirrhosis Patients with Upper Gastrointestinal Bleeding. Biol Med (Aligarh) 10: 423. doi:10.4172/0974-8369.1000423

Page 2 of 6

\section{The main objectives of this study are:}

The analysis of upper gastrointestinal bleeding in cirrhotic patients and the evaluation of different parameters as possible prognostic factors for mortality in those patients.

\section{Material and Methods}

\section{Subjects}

We have made a retrospective study on 647 patients with liver cirrhosis hospitalized for UGB episode in a 5 years period in Gastroenterology and Hepatology Clinic of the Emergency Clinical County Hospital Timisoara.

The liver cirrhosis diagnostic of the patients included in the study was determined by clinical exam together with paraclinical tests (laboratory and imagistic), or by histological exam.

All patients agreed to participate in this study; the study was approved by the local Ethics Committee and was in accordance with the Helsinki Declaration of 1975.

\section{Results}

The studied group included 647 hepatic cirrhosis patients, hospitalized for upper digestive hemorrhage (352 men-54.4\% and 295 women $-45.5 \%$ ), aged between 16 and 84 years with an average age of $54.5 \pm 26.1$ years old. Patient's characteristics and the etiology of cirrhosis are presented in Tables 1 and 2.

\begin{tabular}{|l|l|}
\hline \multicolumn{1}{|c|}{ Average age (mean \pm SD) } & \\
\hline Men & $46 \pm 11.3$ \\
\hline Women & $56.5 \pm 2.1$ \\
\hline Age $>60$ years old (frequency) & $279(43.1 \%)$ \\
\hline Child-Pugh classification (frequency): & \\
\hline - A & $132(20.4 \%)$ \\
\hline - B & $343(53 \%)$ \\
\hline - C & $172(26.5 \%)$ \\
\hline Predisposing factors, cirrhosis complications (frequency): & \\
\hline - NSAID`s & $10(1.5 \%)$ \\
\hline - SBP & $30(4.6 \%)$ \\
\hline - Other infections & $57(8.8 \%)$ \\
\hline - Hepatocellular carcinoma & $38(5.8 \%)$ \\
\hline - Hematemesis and melaena & $393(60.7 \%)$ \\
\hline - Only hematemesis & $157(21.1 \%)$ \\
\hline - Only melena & $76(11.4 \%)$ \\
\hline - Hematochezia & $21(3.2 \%)$ \\
\hline The presence of esophageal varices (frequency): & \\
\hline - 1st grade & $(9.2 \%)$ \\
\hline & \\
\hline
\end{tabular}

\begin{tabular}{|l|l|}
\hline - 2nd grade & $233(36 \%)$ \\
\hline - 3rd grade & $302(46.6 \%)$ \\
\hline - Without esophageal varices & $52(8 \%)$ \\
\hline The presence of gastric varices (frequency) & $110(17 \%)$ \\
\hline Etiology of UGB (frequency): & \\
\hline - Variceal bleeding & $447(69 \%)$ \\
\hline - Nonvariceal hemorrhage & $200(30.9 \%)$ \\
\hline Portal-hypertensive gastropathy & $28(14 \%)$ \\
\hline Peptic ulcer & $134(67 \%)$ \\
\hline Erosive gastritis/duodenitis & $6(3 \%)$ \\
\hline Mallory - Weiss syndrome & $18(9 \%)$ \\
\hline Angiodysplasia & $12(6 \%)$ \\
\hline Gastric cancer & $2(1 \%)$ \\
\hline
\end{tabular}

Table 1: Patient's characteristics.

\begin{tabular}{|l|l|l|l|}
\hline \multicolumn{1}{|c|}{ Cirrhosis etiology } & \multicolumn{1}{|c|}{ Men } & \multicolumn{1}{|c|}{ Women } & \multicolumn{1}{c|}{ Total } \\
\hline Alcohol consumption & 184 & 117 & $301(46.5 \%)$ \\
\hline C viral infection & 90 & 70 & $160(24.7 \%)$ \\
\hline B viral infection & 38 & 29 & $67(10.3 \%)$ \\
\hline HBV+HCV infection & 15 & 5 & $20(3.0 \%)$ \\
\hline HBV+HDV infection & 19 & 6 & $25(3.8 \%)$ \\
\hline Alcohol+virus & 33 & 9 & $42(6.4 \%)$ \\
\hline Autoimmune & 1 & 0 & $1(0.1 \%)$ \\
\hline Primary biliary cirrhosis & 0 & 6 & $6(0.9 \%)$ \\
\hline Hemochromatosis & 3 & 0 & $3(0.4 \%)$ \\
\hline Cryptogenic & 9 & 13 & $22(3.4 \%)$ \\
\hline
\end{tabular}

Table 2: The etiology of cirrhosis.

Almost $70 \%$ of the patients $(n=447)$ had variceal hemorrhage; $83 \%$ $(n=369)$ of these, bled because of the esophageal varices rupture and $17 \%(n=78)$ because of the gastric ones. Almost $70 \%$ of the cases had active bleeding during endoscopy and $20 \%$ had hemorrhagic shock. Death rate was $17 \%$.

In case of those 200 patients with non-variceal bleeding, the most common was the ulcerous etiology, only $50 \%$ had active bleeding during the endoscopy. Death rate was $9 \%$.

Comparing the 2 groups with variceal versus non-variceal bleeding, we found that there are statistically significant differences in active bleeding during endoscopy, also bleeding severity and death rate (Table 3). 


\begin{tabular}{|l|l|l|l|}
\hline \multicolumn{1}{|c|}{ Parameter } & \multicolumn{1}{|c|}{$\begin{array}{c}\text { Non-variceal } \\
\text { UGB(200) }\end{array}$} & \multicolumn{1}{|c|}{$\begin{array}{c}\text { Variceal UGB } \\
(\mathbf{4 4 7 )}\end{array}$} & \multicolumn{1}{c|}{ P-value* } \\
\hline Active hemorrhage & $105(52.5 \%)$ & $304(68 \%)$ & $p=0.0002$ \\
\hline Hemorrhagic shock & $19(9.5 \%)$ & $82(18.3 \%)$ & $p=0.0006$ \\
\hline Death & $18(9 \%)$ & $77(17.2 \%)$ & $p<0.0001$ \\
\hline *Using Chi-test & \multicolumn{3}{|l}{} \\
\hline
\end{tabular}

Table 3: Comparison between the 2 groups.

Following, we have compared the mortality risk factors for the both patients categories: 1st group of variceal UGB versus 2nd group of non-variceal bleeding.

Even in the group with variceal UGB and non-variceal UGB we found significant differences between the group of survivors and the group of deceased, $\mathrm{p}<0.0001$, so the Child-Pugh classes are involved in UGB prognosis, whether the bleeding etiology.

Regarding the hemorrhage severity, for the variceal bleeding $(\mathrm{n}=447)$, mild anemia was found in 120 cases $(26.8 \%)$, moderate anemia was found in 151 cases (33.7\%) and severe anemia was found in 176 cases $(39.3 \%)$, while for non-variceal bleeding $(n=200)$, mild anemia was found in 75 cases (37.5\%), moderate anemia was found in 48 cases (24\%) and severe anemia was found in 77 cases (38.5\%). There was a difference between the two groups regarding the mild anemia $(\mathrm{p}=0.008)$ and moderate anemia $(\mathrm{p}=0.01)$, but not for the severe anemia $(\mathrm{p}=0.9)$.

With chi-square test we have obtained association between anemia's grade and mortality and we have achieved the following results: Chisquare, df51,29,2, p<0.0001, anemia's grade can be considered a predictive factor for mortality (Table 4 ).

\begin{tabular}{|l|l|l|}
\hline \multicolumn{1}{|c|}{ Parameter } & \multicolumn{1}{|c|}{ Survivors $(\mathbf{3 7 0 )}$} & \multicolumn{1}{|c|}{ Deceased $(\mathbf{N}=\mathbf{7 7})$} \\
\hline Mild anemia $(\mathrm{Hb}>8 \mathrm{~g} / \mathrm{dl})$ & $125(33.7 \%)$ & $5(6.4 \%)$ \\
\hline Moderate anemia $(\mathrm{Hb} 6-8 \mathrm{~g} / \mathrm{dl})$ & $112(30.2 \%)$ & $56(72.7 \%)$ \\
\hline Severe anemia $(\mathrm{Hb}<6 \mathrm{~g} / \mathrm{dl})$ & $133(35.9 \%)$ & $16(20.7 \%)$ \\
\hline
\end{tabular}

Table 4: Variceal UGB.

When we analyzed the patients with mild versus severe anemia in the two groups, the survivors and the deceased (Table 5), we found that $\mathrm{p}<0.0001$, relative risk $=1.44$ confidence interval $95 \%$ (1.28-1.61), odds ratio $=12.5$, confidence interval $95 \%,(4.83-32.32)$, therefore there is a relative risk for mortality about 1.4 times bigger in patients with severe versus mild anemia and that the patients with severe anemia had 12.5 more chances to die.

\begin{tabular}{|l|l|l|l|}
\hline \multicolumn{1}{|c|}{ Anemia } & \multicolumn{1}{c|}{ Survivors } & \multicolumn{1}{c|}{ Deceased } & \multicolumn{1}{c|}{ Total } \\
\hline Mild & $125(33.7 \%)$ & $5(6.4 \%)$ & 130 \\
\hline Severe & $133(35.9 \%)$ & $16(20.7 \%)$ & 149 \\
\hline Total & 258 & 21 & 279 \\
\hline
\end{tabular}

Table 5: Mild anemia versus severe anemia.
For the patients with hemorrhagic shock by variceal bleeding, the chi-square test demonstrates the relation between hemorrhagic shock and death $\mathrm{p}<0.0001$. Strength of the association: $\mathrm{RR}=2.85,95 \% \mathrm{CI}$ (2.09-3.80), OR=31.7, 95\%CI (16.90-59.69), so the patients who had variceal bleeding had 31.7 more chances for hemorrhagic shock. For the group with non-variceal bleeding, $\mathrm{p}=0.008$, Strength of association: Relative Risk $=1.36,95 \%$ confidence interval, 0.97 to 1.89 , Odds ratio $=4.85,95 \%$, confidence interval 1.61 to 14.58 , therefore we can conclude that the hemorragic shock is a predictive factor for mortality invariceal and nonvariceal bleeding.

Analyzing the data by the cirrhosis etiology by virus (124 cases) and by alcohol (155 cases), we observe that the differences between the groups are not significant, $\mathrm{p}=0.30$. Although the number of deaths was bigger in the alcoholic patients group $(11.1 \%$ vs. $6.3 \%, \mathrm{p}=0.4)$, the differences in this study were not statistically significant, therefore we can conclude that the prognostic of variceal upper digestive bleeding is not influenced by the etiology of liver disease.

We evaluated the possible predictive factors for early mortality and rebleeding in patients with variceal hemorrhage, by dividing the batch of 647 patients into 2 categories as follows:

1. Patients without rebleeding $(\mathrm{N}=289)$ vs. patients who rebleed $(\mathrm{N}=158)$ and,

2. Survivors $(\mathrm{N}=370)$ vs. deceased $(\mathrm{N}=77)$, we tried to identify possible risk factors for prediction of rebleeding and early mortality by analyzing the following parameters: the degree of hepatic insufficiency (Child-Pugh classification and MELD score, albumin, cholinesterase, bilirubin), the severity of bleeding (anemia, hemorrhagic shock,), endoscopic parameters (variceal grade, active bleeding at endoscopy), coagulation disorders (platelets count and INR), etiology of cirrhosis, decompensation of the underlying disease (vascular, parenchymatous) (Tables 6 and 7).

Comparing the initial MELD score to the one at the time of death due to variceal haemorrhage, we observed a statistically significant increase, mean value: $18.07 \pm 7.74$ in the first episode versus $31.8 \pm$ 7.11 to death, $\mathrm{P}<0.0001, \quad$ AUROC $=0.91$, 95\%CI (0.83-0.99). Considering the MELD score at first hemorrhage and the survival period (in months) from the first episode of bleeding till death, we analyzed the survival duration based on the degree of liver failure by using Kaplan Meier curve (Tables 8 and 9).

In studied cohort, survival at 1 year was $38.8 \%$, at 2 years $-32.3 \%$, at 4 years $-9 \%$, at 5 years all patients died.

\begin{tabular}{|c|c|}
\hline Parameter & P value* $^{*}$ \\
\hline Age & 0.01 \\
\hline Bilirubin & 0.03 \\
\hline MELD score & 0.0008 \\
\hline Ascites & 0.0002 \\
\hline *Using univariate analysis & \\
\hline
\end{tabular}

Table 6: Rebleeding. 
Page 4 of 6

\begin{tabular}{|l|l|}
\hline \multicolumn{1}{|c|}{ Parameter } & \multicolumn{1}{c|}{ P value* $^{*}$} \\
\hline Male & 0.03 \\
\hline Albumin & 0.0001 \\
\hline MELD score & $<0.0001$ \\
\hline Rebleeding & 0.005 \\
\hline Encephalopathy & $<0.0001$ \\
\hline Ascites & 0.02 \\
\hline Anemia & 0.002 \\
\hline *Using univariate analysis & \\
\hline
\end{tabular}

Table 7: Mortality.

\begin{tabular}{|c|c|c|}
\hline MELD score & $\begin{array}{c}\text { Average survival duration } \\
\text { (months) }\end{array}$ & $\mathbf{9 5 \%} \mathbf{~ C l}$ \\
\hline 6 & $57 \pm 3$ & $(51-63)$ \\
\hline 11 & $33 \pm 8$ & $17-49$ \\
\hline 17 & 24 & $24-24$ \\
\hline 18 & $15 \pm 3$ & $9-21$ \\
\hline 20 & 12 & $12-12$ \\
\hline 22 & 12 & $12-12$ \\
\hline 26 & $9 \pm 4$ & $2-15$ \\
\hline 29 & 3 & $3-3$ \\
\hline 30 & $4 \pm 1$ & $1-6$ \\
\hline
\end{tabular}

Table 8: Survival analysis based on MELD score.

\begin{tabular}{|c|c|c|}
\hline Months & No. of deaths & $\%$ \\
\hline 2 & 2 & 6.4 \\
\hline 6 & 8 & 26 \\
\hline 12 & 19 & 61 \\
\hline 24 & 21 & 68 \\
\hline 48 & 28 & 90 \\
\hline 60 & 31 & 100 \\
\hline
\end{tabular}

Table 9: Mortality rate related.

\section{Statistical Analysis}

The statistical analysis used the MS Excel database and was performed using SPSS v20 (IBM) for Windows and Graph Pad Prism v5 for Windows.

The Kolmogrov-Smirnov test was used for testing the distribution of numerical variables. Mean value and standard deviation were calculated for numerical variables with normal distribution, while in cases of non-normal distribution, median values and range intervals

were used, whereas categorical variables were reported as the number (proportion) of patients with/without the specific characteristic. Student's t-test was used for group comparisons of continuous variables with a normal distribution and nonparametric tests (MannWhitney U-test) was applied for variables with non-normal distribution. Group comparisons of categorical variables were performed using Pearson's Chi-test $\left(\mathrm{x}^{2}\right.$-test). We used the KaplanMeier curve for survival analysis. In order to identify the parameters involved and associated with the mortality, we used the univariate and multivariate analysis, by using the logistic regression. Ninety-five percent confidence intervals were calculated for each predictive test and a $\mathrm{p}$ value $<0.05$ was considered to reveal statistical significance.

\section{Discussion}

Upper gastrointestinal bleeding is a common life-threatening condition in which mortality rate is from 4 to $15 \%$ [6-8]. Upper GI bleeding either from peptic ulcer or esophegeal varices is a major complication of cirrhosis [9]. In cirrhotic patients, variceal bleeding has been studied by many researchers, however, 30 to $40 \%$ of cirrhotic patients who bleed may have nonvariceal sources, and the hemorrhage is frequently caused by gastro-duodenal ulcers. Most studies focus on the characteristics of the variceal bleeding, there are few reports in which nonvariceal and variceal bleeding are analyzed together [10-12].

In this study we analyzed the clinical outcomes of a single-center cohort of cirrhotic patients after an acute bleeding in day-to-day clinical practice. The main intentions were to establish the etiology of bleeding in a cirrhotic patient and to discover the prognostic factors in variceal and nonvariceal hemorrhage.

Cirrhosis is the most advanced form of liver disease and variceal hemorrhage is one of its lethal complications. Over half of the patients with cirrhosis will develop varices. The risk of bleeding once esophageal varices formed is $20 \%$ to $35 \%$ within 2 years [13]. We had a $70 \%$ incidence of variceal bleeding with an in-hospital mortality rate of $17 \%$. The reported mortality rate from first episode of variceal bleeding is $17 \%$ to $27 \%$ [14].

Our mortality rate of $17 \%$ is consistent with the experience from other centers. Pauwels et al. showed that in-hospital mortality in cirrhotic patients admitted with variceal bleeding has decreased by $50 \%$ over the past 15 years [15]. Afessa and Kubilis in the year 2000 reported an in-hospital mortality rate of $21 \%$ in bleeding cirrhotics [16]. More recently, Chalasani et al. in a large study over 3 years reported the inhospital mortality to be $14.2 \%$ [17]. Similar decline in hospital mortality has been reported in other studies too [18-21].

We present the data for variceal hemorrhage but frequently cirrhotic patients bleed from another sources. We had a nonvariceal source of bleeding in $30 \%$ of our cirrhotic patients, peptic ulcer being the predominant etiology $(67 \%)$. The incidence of bleeding ulcer in our batch was $20.7 \%$, comparable with the one reported in other studies [22-27]. The mortality rate in nonvariceal bleeding group was $9 \%$. González reported in his study a $13.8 \%$ mortality rate in a batch of 160 cirrhotic patients with nonvariceal bleeding.

In our study the mortality increased with the degree of hepatic dysfunction in patients with all known sources of bleeding as well as in cases with variceal bleeding. Severe anemia is a risk factor for mortality in variceal hemorrhage but not in patients with nonvariceal bleedings in our data, however, acute massive bleeding with hemorrhagic shock increases the mortality risk. Our data confirm the results published in 
another studies [28], that acute variceal bleeding and liver insufficiency are independent prognostic risk factors. Amitrano pointed in his article the relevance of the degree of liver failure on the current management strategies of variceal bleeding. This study compares nonvariceal bleeding in cirrhotic vs. noncirrhotic patients. The novelty of our study consists in the evaluation of nonvariceal versus variceal bleeding impact in cirrhotic patients. In the literature we did not found a comparison of variceal and nonvariceal hemorrhage.

Various studies evaluated different parameters as possible predictive factors for rebleeding and mortality in variceal hemorrhage. Only variceal size and the hepatic failure were identified as predictive factors for mortality $[29,30]$.

Despite the fact that the prognosis of cirrhotic patients with variceal bleeding has improved over the last few decades, however, mortality remains high at these patients. The key point in approaching these patients is to determine patients with major risk for bleeding.

The factors which have the most powerful influence over mortality are: MELD score, serum albumin, encephalopathy, rebleeding and severe anemia and the main predictors of rebleeding are: MELD score and presence of ascites.

Various studies have assessed the accuracy of MELD score compared with Child-Pugh classification for prognostic evaluation of patients with liver cirrhosis. Regarding the prognosis of patients with variceal bleeding there are conflicting data in the literature so that the superiority of MELD score is still a subject of debate. Therefore we tried to estimate the survival time after the first episode of variceal hemorrhage based on the value of MELD score.

We had 77 patients with liver cirrhosis who died after an episode of variceal hemorrhage. Out of the 77 deaths in this group, 46 patients died after the first episode of bleeding and 31 had multiple episodes of bleeding. We calculated MELD score at the first bleeding and at death noting the survival period from the first episode to death to see the influence of the degree of liver failure on prognosis.

For optimal management of cirrhotic patients with variceal bleeding is important to identify risk factors of recurrent bleeding and mortality. Studies published in the literature have tested different parameters as prognostic factors in variceal hemorrhage: Alcoholic cirrhosis, variceal grade, thrombocytopenia, hypoalbuminemia, hyperbilirubinemia, encephalopathy, Child-Pugh class, MELD scores [31-35].

In our study the most important predictive factors for mortality are: MELD score, serum albumin level, encephalopathy, severe anemia and rebleeding and the predictive factors for rebleeding are MELD score and large ascites.

\section{Conclusion}

We found in our study that variceal bleeding is more aggressive than nonvariceal hemorrhage, showing more active bleeding at the time of endoscopy, inducing hemorrhagic shock more frequently and higher mortality rate.

Hepatic insufficiency in patients with all sources of bleeding is an independent risk factor for mortality in cirrhotic patients.

Severe anemia turn to be a risk factor for mortality in variceal hemorrhage but not in patients with nonvariceal sources of hemorrhage, however, acute massive bleeding with hemorrhagic shock increases the mortality risk.
MELD score, serum albumin level, encephalopathy, severe anemia and rebleeding are prognostic factors for mortality and the predictive factors for rebleeding in cirrhotic patients with variceal hemorrhage are MELD score and large ascites.

\section{Authorship}

All authors contributed to this work. Adrian Goldis wrote the paper, Adrian Goldis, Iulia Ratiu designed and supervised the study; Iulia Ratiu, Adrian Goldis, Raluca Lupusoru performed research; Raluca Lupuşoru analyzed the data; Iulia Ratiu, Adrian Goldis and Ramona Goldis revised the manuscript. All authors prepared and agreed to the final version of the manuscript.

\section{Conflict of Interest}

None of the authors has a financial relationship with a commercial entity that has an interest in the subject of this manuscript.

\section{References}

1. D'Amico G, Pagliaro L, Bosch J (1995) The treatment of portal hypertension: a meta-analytic review. Hepatology 22: 332-354.

2. McCormick PA, O'Keefe C (2001) Improving prognosis following a first variceal hemorrhage over four decades. Gut 49: 682-685

3. Imazu H., Seewald S, Omar S, Zhong Y, Soehendra N (2005) Endoscopic treatment for portal hypertension: what's new in the last 12 months. Endoscopy 37: 116-121

4. Krige JE, Kotze UK, Bornman PC, Shaw JM, Klipin M (2006) Variceal recurrence, reebleeding and survival after endoscopic injection sclerotherapy in 287 alcoholic cirrhotic patients with bleeding esophageal varices. Ann Surg 244: 764-770

5. Triantos CK, Burroughs AK (2007) Prevention of the development of varices and first portal hypertension bleeding episode. Best Pract Clin Gastroenterology 21:31-42.

6. Laine L (2007) Upper gastrointestinal bleeding. Clinical Update American Society of Gastrointestinal Endoscopy 14: 1-4.

7. Marmo R, Koch M, Cipolletta L, Capurso L, Pera A, et al. (2008) Predictive factors of mortality from nonvariceal upper gastrointestinal hemorrhage: a multicenter study. Am J Gastroenterol 103: 1639-1647.

8. Sung JJ, Tsoi KK, Ma TK, Yung MY, Lau JY, et al. (2010) Causes of mortality in patients with peptic ulcer bleeding: a prospective cohort study of 10,428 cases. Am J Gastroenterol 105: 84-89.

9. Hayes PC, Collier JD, Chapman RW (2006) Liver and biliary tract disease (20thedn) In: Davidson's principles \& practice of medicine. Churchill Livingstone, London. pp: 935-997.

10. Afessa B, Kubilis PS (2000) Upper gastrointestinal bleeding in patients with hepatic cirrhosis: clinical course and mortality prediction. Am J Gastroenterol 95: 484-489.

11. Klebl F, Bregenzer N, Schofer L, Tamme W, Langgartner J, et al. (2005) Risk factors for mortality in severe upper gastrointestinal bleeding. Int J Colorectal Dis 20: 49-56.

12. Imperiale TF, Dominitz JA, Provenzale DT, Boes LP, Rose CM, et al. (2007) Predicting poor outcome from acute upper gastrointestinalhemorrhage. Arch Intern Med 167: 1291-1296.

13. Muntaner L, Altamirano JT, Augustin S, Gonzalez A, Esteban R, et al. (2010) High doses of $\beta$-blockers and alcohol abstinence improve longterm rebleeding and mortality in cirrhotic patients after an acute variceal bleeding. Liver International 30: 1123-1130.

14. Burza MA, Marschall HU, Napoleone L, Molinaro A (2017) The 35-year odyssey of beta blockers in cirrhosis: any gender difference in sight? Pharmacol Res 119: 20-26. 
15. Chalasani N, Kahi C, Francois F, Pinto A, Marathe A, et al. (2003) Improved patient survival after acute variceal bleeding: a multicenter, cohort study. Am J Gastroenterol 98: 653-659.

16. Carbonell N, Pauwels A, Serfaty L, Fourdan O, Levy VG, et al. (2004) Improved survival after variceal bleeding in patients with cirrhosis over the past two decades. Hepatology 40: 652-659.

17. Krige JE, Kotze UK, Distiller G, Shaw JM, Bornman PC (2009) Predictive factors for rebleeding and death in alcoholic cirrhotic patients with acute variceal bleeding: a multivariate analysis. World J Surg 33: 2127-2135.

18. González-González JA, García-Compean D, Vázquez-Elizondo G, GarzaGalindo A, Jáquez-Quintana JO, et al. (2011) Nonvariceal upper gastrointestinal bleeding in patients with liver cirrhosis. Clinical features, outcomes and predictors of in-hospital mortality. A prospective study. Ann Hepatol 10: 287-295

19. Brunner F, Berzigotti A, Bosch J (2017) Prevention and treatment of variceal haemorrhage in 2017. Liver Int 37: 104-115.

20. Mohammed SE, Abdo AE, Mudawi HM (2016) Mortality and rebleeding following variceal haemorrhage in liver cirrhosis and periportal fibrosis. World J Hepatol 8: 1336-1342.

21. Kamalaporn P, Sobhonslidsuk A, Jatchavala J, Atisook K, Rattanasiri S, et al. (2005) Factors predisposing to peptic ulcer disease in asymptomatic cirrhotic patients. Aliment Pharmacol Ther 21: 1459-1465

22. Auroux J, lamarque D, Roudot TF, Deforges L, Chaumette MT, et al. (2003) Gastroduodenal ulcer and erosions are related to portal hypertensive gastropathy and recent alcohol intake in cirrhotic patients. Dig Dis Sci 48: 1118-1123.

23. Shahin WA, Abdel-Baset EZ, Nassar AK (2001) Low incidence of Helicobacter pylori infection in patients with duodenal ulcer and chronic liver disease. Scand J Gastroenterol 36: 479-484.

24. Burra P, Di Mario F, Gottardello L, Dalri L, Salvagnini M, et al. (1990) Peptic ulcer and liver cirrhosis. Clinico-epidemological considerations. Minerva Med 81: 119-128.

25. Bambha K, Kim WR, Pedersen R, Bida JP, Kremers WK, et al. (2008) Predictors of early re-bleeding and mortality after acute varicealhaemorrhage in patients with cirrhosis Gut 57: 814-820.
26. Amitrano L, Guardascione MA, Menchise A, Manguso F, Balzano A (2011) Management of variceal haemorrhage in cirrhosis: the relevance of the risk stratification Gut 60: 1303-1303.

27. Mohammad AN, Morsy KH, Ali MA (2016) Variceal bleeding in cirrhotic patients: What is the best prognostic score? Turk J Gastroenterol 27: 464-469.

28. Benedeto-Stojanov D, Nagorni A, Bjelakovic G, Milanovoc J, Stojanov D (2006) Predictive Factors of Bleeding From Esophageal Varices in Patients with Liver Cirrhosis and Portal Hypertension. FACTA UNIVERSITATIS Series: Medicine and Biology 13: 164-167.

29. Limquiaco J (2006) Clinical Predictors of Bleeding from Esophageal Varices: A Retrospective. Study Phil J of Gastroenterology 2: 103-111.

30. Cales P, Masliah C, Bernard B, Garnier PP, Silvain C, et al (2001) Early administration of vapreotide for variceal bleeding in patients with cirrhosis. French Club for the Study of Portal Hypertension. N Engl J Med 344: 23-28.

31. Augustin S, Muntaner L, Altamirano JT, Gonzalez A, Saperas E, et al. (2009) Predicting early mortality after acute variceal hemorrhage based on classification and regression tree analysis. Clin Gastroenterol Hepatol 7: 1347-1354.

32. Benedeto-Stojanov D, Nagorni A, Bjelakovic G, Stojanov D, Mladenovic B, et al. (2009) The model for the end-stage liver disease and Child-Pugh score in predicting prognosis in patients with liver cirrhosis and esophageal variceal bleeding. Vojnosanit Pregl 66: 724-728.

33. Amitrano L, Guardascione MA, Manguso F, Bennato R, Bove A, et al. (2012) The effectiveness of current acute variceal bleed treatments in unselected cirrhotic patients: refining short-term prognosis and risk factors. Am J Gastroenterol 107: 1872-1878.

34. Lyles T, Elliott A, Rockey DC (2014) A risk scoring system to predict inhospital mortality in patients with cirrhosis presenting with upper gastrointestinal bleeding. J Clin Gastroenterol 48: 712-720.

35. Constantin VD, Socea B, Sireteanu G, Popa F (2008) Epidemiological aspects and risk factors in the outcome of variceal eso-gastric bleeding at cirrhosis patients. JAQM 3: 316-324. 